\title{
O ensino de gramática na contemporaneidade: delimitando e atravessando as fronteiras na formação inicial de professores de língua portuguesa $^{1}$
}

\section{Contemporary grammar teaching: Specifying and crossing borders in Portuguese teachers' initial training}

\author{
Kleber Aparecido da Silva* \\ Universidade de Brasília - UnB - Brasília - Distrito Federal/Brasil \\ Universidade Estadual Paulista - São José do Rio Preto - São Paulo/Brasil \\ Eloisa Pilati** \\ Universidade de Brasília - UnB - Brasília - Distrito Federal/Brasil \\ Juliana de Freitas Dias*** \\ Universidade de Brasília - UnB - Brasília - Distrito Federal/Brasil
}

\begin{abstract}
RESUMO: Partindo dos avanços obtidos nas pesquisas desenvolvidas no bojo da Linguística Aplicada e das novas perspectivas apresentadas neste campo de investigação, o presente artigo traz uma proposta de ensino cujo maior objetivo é o superar uma concepção tradicional de língua e de ensino de língua ir ao encontro de uma concepção de linguagem capaz de subsidiar não só novas metodologias, mas, principalmente, capaz de remodelar o próprio conteúdo ensinado. Para tanto, são feitas reflexões sobre o ensino de gramática, tendo como pano de fundo as diretrizes curriculares dos cursos de Letras, discussóes sobre o ensino de gramática presentes nos cursos de formação de professores de línguas, tais como os PCN
\end{abstract}

\footnotetext{
${ }^{1}$ Agradecemos a colega Helena da Silva Guerra Vicente da Universidade de Brasília (UnB) pelos comentários e pela leitura criteriosa deste trabalho, e aos pareceristas desta revista pelas sugestões. Assumimos, todavia, toda a responsabilidade pelas considerações feitas.

* kleberunicamp@yahoo.com.br

** eloisapilati@gmail.com

***ju.freitas@gmail.com
} 
(1998), e propostas de autores, como Possenti (1996), Neves (2002), Lobato (2003) e Vieira e Brandão (2007). Por fim, são apresentados possíveis parâmetros para a constituição de novas práticas pedagógicas para o ensino de gramática e para a formação inicial do professor de língua portuguesa, com base nas perspectivas inatista e crítica da linguagem.

PALAVRAS-CHAVE: ensino de gramática; parâmetros para a constituição de novas práticas pedagógicas; Linguística Aplicada

ABSTRACT: This paper, following the advances in the research done within Applied Linguistics and the new perspectives put forward by these works, proposes a new approach to teaching in which the main goal is (i) to overcome a traditional concept of language and language teaching, and (ii) to look towards a concept of language that is not only able to support the implementation of new methodologies, but also to reshape their own contents. In order to do so, we reflect on the teaching of grammar in light of our Letters courses curricula, and we discuss the teaching of grammar raised in language teacher training guidelines, such as the PCN and proposals by authors such as Possenti (1996), Neves (2002), Lobato (2003) and Vieira e Brandão (2007). Finally, we present possible parameters for the constitution of new pedagogical practices for the teaching of grammar and Portuguese as a native language teachers education.

KEYWORDS: the teaching of grammar; parameters for the constitution of new pedagogical practices; Applied Linguistics.

“(...) Uma fronteira não é o ponto onde algo termina, mas, como os gregos reconheceram, a fronteira é o ponto a partir do qual algo começa a se fazer presente."

Martin Heidegger

\section{Introdução}

O estudo do ensino de gramática é, sem dúvida, um dos campos de investigação que tem se tornado fértil na Linguística Aplicada (LA) brasileira e / ou áreas afins, como pode ser observado em inúmeros periódicos da área ("Revista Brasileira de LA"; "Linguagem \& Ensino"; "Trabalhos em LA"; "D.E.L.T.A"; "The ESPecialist"; "Contexturas: Ensino Crítico de Língua Inglesa"), em livros de estudiosos da linguagem (LEFFA, 2008; VIEIRA; BRANDÃO, 2007; MENDONÇA, 2006, entre outros), e até mesmo em coletâneas sobre o tema em questão (DUTRA; MELLO, 2004).

Em termos educacionais, segundo a visão tradicional de ensino de gramática, grande parte do tempo e esforço gasto por professores e alunos durante o processo escolar é destinada ao estudo da metalinguagem de análise da língua(gem), com exercícios contínuos de prescrição gramatical, estudo de 
regras e resoluções de problemas. Geralmente, os conteúdos linguísticos são apresentados em blocos estanques, cuja divisão compartimentaliza a língua como algo descontínuo e desconexo. Além disso, o ensino de gramática aparece desligado de qualquer utilização prática, tendo o seu objetivo final centrado em si mesmo e os mesmos tópicos gramaticais são repetidos ano após ano, durante os doze anos que constituem a trajetória oficial de ensino.

Ainda nesse sentido, a falsa democratização do ensino, de acordo com Geraldi (1991), ampliou inconsequentemente o quadro escolar e a solução encontrada diante do despreparo docente foi o acesso ao livro didático, quase na condição de substituto de cursos necessários, ou seja, como um manual que por si só ensinasse ao professor como ensinar e outro que ensinasse ao aluno tudo que fosse possível. Ambos agentes do processo educativo são transformados em meras máquinas reprodutoras, de sujeitos agentes ideais passam a sujeitos pacientes reais.

Diante dos avanços nas pesquisas que investigam a língua(gem) é possível desvendar as diversas concepções de língua(gem) e de gramática(s) que estão presentes nas diferentes práticas teóricas e educacionais da contemporaneidade. E diante dessas novas perspectivas, superar uma concepção tradicional de língua e de ensino de língua vai ao encontro de uma concepção de língua(gem) capaz de subsidiar não só novas metodologias, mas, principalmente, capaz de remodelar o próprio conteúdo ensinado.

Levando-se em consideração esse interesse e a ampla diversidade de focos, o presente artigo visa suscitar algumas reflexões acerca das perspectivas adotadas nos cursos de formação inicial de professores de língua portuguesa e apresentar um aparato teórico para a LA e / ou áreas afins, visando, por sua vez, a (re)construção de uma abordagem para o ensino de gramática na contemporaneidade.

É relevante destacar que as reflexões propostas no presente artigo estão assentadas em um diálogo transdisciplinar, uma vez que as diferentes práticas de pesquisa acadêmica e de sala de aula de cada um de nós, autores, estão entrelaçadas sob a ótica da transdisciplinaridade. Chouliaraki e Fairclough (1999) definem a transdisciplinaridade no sentido de interpenetração de disciplinas, de modo que suas categorias sejam colocadas em risco, extrapolando a interdisciplinaridade que consiste apenas em aplicar as categorias de diferentes disciplinas para o mesmo problema, sem, contudo, modificá-las. A transdisciplinaridade, segundo os autores (1999, p. 2), está assentada na abertura de uma teoria para o diálogo com outras, "de forma que a lógica de uma teoria seja 'posta em ação' dentro de outra, sem a última ser reduzida à primeira”. 
Para tanto, este artigo subdivide-se em quatro seções além da parte introdutória. Na primeira seção, apresentaremos breves reflexões concernentes ao ensino de gramática, tendo como pano de fundo resultados de reflexões sobre o ensino da língua e as diretrizes curriculares dos cursos de Letras. A seguir, na segunda seção, apresentaremos discussões sobre o ensino de gramática nos cursos de formação inicial de professores de línguas, percorrendo dos PCN à proposta de autores, como Possenti (1996), Neves (2002) e Vieira e Brandão (2007). Os pressupostos que serão apresentados nesta seção serão retomados na seção seguinte, visto que abrangeremos (novas) perspectivas no ensino de língua portuguesa. Na terceira seção, esboçaremos a elaboração de possíveis parâmetros para a constituição de novas práticas pedagógicas na formação inicial do professor de língua. Na quarta e última seção, finalizaremos o artigo com breves considerações.

\section{Reflexões sobre ensino de gramática na realidade educacional brasileira}

O ensino de gramática no contexto educacional brasileiro tem sido primordialmente prescritivo, baseado nas regras da gramática normativa tida como o manual do bem falar (ILARI, 1992). A língua portuguesa é, na prática, muitas vezes considerada homogênea, apesar de o Brasil ser um país marcado por grandes contrastes, aliás, em vários sentidos. A variedade padrão é aquela ensinada na escola, instituição que representa uma força corretiva e unificadora da língua. A despeito do que preconizam os manuais gramaticais, a heterogeneidade linguística está estabelecida no país e é influenciada tanto por fatores diatópicos, geográficos, quanto por fatores diastráticos, sociais. Devido ao acesso limitado à ampla e efetiva escolarização, as diferenças linguísticas tornam-se acentuadas e, sobretudo, cada vez mais distantes da norma culta.

De um lado, há os que defendem o respeito com relação à variedade linguística das classes populares, pois sua linguagem é considerada tão válida para a comunicação quanto a língua padrão. Por outro lado, há os que afirmam a necessidade de as classes populares aprenderem a usar a variedade socialmente privilegiada, visto que a posse dessa linguagem constitui instrumento fundamental e indispensável na luta pela superação das desigualdades sociais (POSSENTI, 1992). Mas o que gostaríamos de problematizar inicialmente é o seguinte: diante da variedade linguística do português, como fica a questão do ensino? Qual variedade deve ser ensinada pelo professor de língua portuguesa? 
A primeira corrente expressa uma ideia muito simplista da língua, uma vez que restringe seu uso apenas à comunicação, ignorando as demais concepções de linguagem. A língua(gem), além de se prestar ao ato comunicativo, configura a expressão do pensamento, sendo, sobretudo, uma forma de interação humana, política e social. É sob essa ótica que defendemos que as atividades de ensino devem oportunizar aos alunos o domínio de um sistema valorizado, ou seja, da norma padrão, sem que isso signifique depreciação da variante linguística de seu grupo social e regional de origem.

Compartilhando dessa opinião encontram-se vários estudiosos da língua(gem) (POSSENTI, 1992; GERALDI, 1991, entre outros) que defendem a aplicação de um ensino multilíngue, no sentido da "assimilação social" e / ou da "integração social". Nesse sentido, a escola deve funcionar como instrumento de transformação da sociedade e o trabalho escolar deve incluir "as variantes conviventes em nível de igualdade e de interesse, sem escamotear para os alunos as avaliações sociais para cada uma delas" (SILVA, 1997, p. 27).

Podemos dizer, então, que os pesquisadores brasileiros têm uma noção bastante clara de que, em um ensino democrático, todas as variedades do português podem e devem ser trabalhadas em sala de aula e as avaliaçôes sociais sobre cada uma delas não devem ser negligenciadas. Outro aspecto importante é que a variedade considerada de prestígio pela sociedade deve ser bem explorada, pois o conhecimento e o uso dessa variedade por parte dos alunos serão úteis na sua relação com a sociedade. A nova questão que se coloca nesse momento é a necessidade urgente de se viabilizar esse ensino em sala de aula. Em outras palavras, como auxiliar professores a implementar em sala de aula o trabalho com as diversas variedades linguísticas e como auxiliar o professor nessa nova missão?

O caminho, sem dúvida, passa pelas ciências da linguagem em seus diversos aspectos. Somente com a contribuição dos estudos linguísticos é que poderemos encontrar uma forma de melhorar o ensino de língua. No entanto, como já notado por outros pesquisadores, por exemplo, Neves (2002), nos cursos de Letras, de modo geral, não há uma integração nítida entre o que os alunos aprendem sobre as diferentes teorias e modos de fazer linguística e a sua atuação em sala de aula. Ou seja, os alunos egressos do curso de Letras parecem esquecer as aulas de Linguística e chegam à sala de aula sem ter uma noção clara do que deve ser ensinado aos alunos, para que serve, ou deve servir, uma teoria formalista ou funcionalista da linguagem e qual a implicação de se adotar uma ou outra hipótese para o ensino de línguas. 
Nesse sentido é fundamental que o professor tenha clareza das concepções de linguagem relacionadas ao ensino gramatical, pois, segundo Travaglia (2002), a maneira como se concebe a natureza fundamental da língua(gem) afeta profundamente o fazer pedagógico do professor de língua em seu trabalho com os alunos. O que se pode constatar é que apesar de todo o conhecimento desenvolvido pelos estudos da língua(gem) em relação às características da(s) gramática(s) do português brasileiro, por exemplo, esses conhecimentos não têm chegado à sala de aula ou não têm sido usados pelos professores como elementos de reflexão para que os alunos possam entender as diferenças entre variedades coloquiais e a variedade padrão da língua. Outro problema que parece vir ocorrendo é a mera substituição de gramáticas, da normativa, tem se passado para a descritiva, mas as atividades param na classificação, na metaliguagem. Ainda não se chegou ao ponto de usar os conhecimentos obtidos por meio das pesquisas linguísticas para despertar no aluno uma reflexão sobre o funcionamento da língua e os efeitos decorrentes da escolha de diferentes estruturas, ou dos efeitos de sentido de uma ou outra forma de uso. Ou seja, ainda não se chegou ao nível de reflexão crítica sobre a língua.

Essa distância, em tese, não deveria existir. Analisemos, por exemplo, o parecer da CNE/CES 492 de 3 de abril de 2001, que apresenta as diretrizes curriculares do curso de Letras: entre os objetivos a serem alcançados pelos graduandos em Letras está a formação de profissionais a) capazes de lidar de forma crítica com as linguagens, especialmente a verbal, nos contextos oral e escrito, b) que dominem o uso da língua, objeto de seus estudos, em termos de sua estrutura, funcionamento e manifestações culturais, além de ter consciência das variedades linguísticas e culturais e c) capazes de refletir teoricamente sobre a linguagem.

Espera-se que o aluno graduado em Letras esteja preparado para lidar de forma crítica com a linguagem, refletindo teoricamente sobre ela. Ainda de acordo com essas diretrizes, dentre as competências a serem desenvolvidas durante a formação do futuro professor estão: a) domínio do uso da língua portuguesa nas suas manifestações oral e escrita em termos de recepção e produção de textos, b) a reflexão analítica e crítica sobre a linguagem como fenômeno psicológico, educacional, social, histórico, cultural, político e ideológico; c) domínio dos conteúdos básicos que são objeto dos processos de ensino e aprendizagem no ensino fundamental e médio; d) domínio de métodos e técnicas pedagógicas que permitam a transposição dos conhecimentos para os diferentes níveis de ensino. 
Saber fazer essa transposição entre os conhecimentos aprendidos durante sua graduação e os conhecimentos a serem apresentados aos alunos deveria ser uma das competências dos professores de língua, mas parece que esse é o novo obstáculo a ser transposto pelos novos profissionais e pela universidade na contemporaneidade. Em outras palavras, o que precisa ser, de fato, explorado nesse contexto é o estudo de métodos e técnicas que sejam capazes de desenvolver os conhecimentos linguísticos dos graduandos de forma eficiente, para tornálos verdadeiramente proficientes nas diversas variedades de uso de seu idioma a fim de que a transposição didática seja realizada com segurança e clareza.

Em resumo, as pesquisas linguísticas comprovam a não homogeneidade da língua portuguesa, os pesquisadores se colocam a favor da presença em sala de aula das diversas variedades linguísticas existentes, mas ainda não há uma metodologia que auxilie os professores a transformar essas ideias em formas de ação pedagógica. É exatamente a construção de uma metodologia capaz de incluir essas crenças com foco voltado para a prática que deve ser trabalhada nos cursos de Letras, para que o docente ao chegar em sala de aula saiba como conciliar o ensino da variedade padrão com a reflexão sobre a língua e com a reflexão sobre as variedades linguísticas.

\section{(Novas) Perspectivas de ensino de língua portuguesa}

Apresentaremos a seguir, propostas apresentadas na literatura especializada na área de estudos da língua(gem) sobre a questão do ensino da gramática. $\mathrm{O}$ objetivo da sistematização dessas propostas é auxiliar os professores na transposição dos conhecimentos linguísticos para a sala de aula, tarefa que será mais desenvolvida na próxima seção. Inicialmente, apresentaremos os pressupostos que subsidiam a documentação curricular oficial brasileira - os chamados "Parâmetros Curriculares Nacionais" (doravante PCN) e analisaremos, em seguida, as propostas de estudiosos da língua(gem) (POSSENTI, 1996; NEVES, 2002; VIEIRA; BRANDÃO, 2007). Em todas as propostas, procuraremos elencar as concepçóes de linguagem adotadas, as metodologias e os exemplos práticos oferecidos ao professor. Ao final desta seção, apresentaremos uma tabela resumida com base nas quatro propostas destacadas.

Os PCN (1998, p. 24) adotam uma perspectiva sociointeracionista da linguagem. Segundo essa perspectiva, "a língua é um sistema de signos histórico e social que possibilita ao homem significar o mundo e a realidade. Assim, aprendê-la é aprender não só conhecer as palavras mas também os seus significados culturais e, com eles, os modos pelos quais as pessoas do seu meio 
social entendem e interpretam a realidade e a si mesmas." Seguindo essa concepção de língua, o documento se coloca contrário ao ensino da gramática prescritiva que se centra na repetição de nomenclaturas gramaticais como eixo principal e desvinculado de um contexto de uso.

Em relação à opção metodológica sugerida pelos $\mathrm{PCN}$, a ideia é que se utilize o saber linguístico do aluno como ponto de partida para a decisão daquilo que será desenvolvido, tendo como referência o valor da linguagem nas diferentes esferas sociais (PCN - EM, 1998, p. 17). Sugere-se que sejam desenvolvidas atividades interativas em que a língua seja considerada um processo discursivo do pensamento simbólico, valorizando a natureza social e interativa da linguagem. $O$ trabalho do professor deve centrar-se no objetivo de desenvolvimento e sistematização da linguagem interiorizada pelo aluno, incentivando sua verbalização e o domínio de outras utilizadas em diferentes esferas sociais. Um exemplo de atividade sugerida é a comparação nos níveis semânticos, morfológicos e sintáticos de diferentes variedades linguísticas de diferentes línguas.

Possenti (1996, p. 70) adota a hipótese de que se deve conceber a língua como algo internalizado, ou seja, de que existe "uma gramática na mente dos falantes que funciona como a fonte das formas linguísticas produzidas". Para o autor, o papel da escola não é ensinar uma variedade no lugar da outra, mas, sim, criar condições para que os alunos aprendam também as variedades que não conhecem. A aceitação de que o objetivo prioritário da escola seja permitir a aquisição da gramática internalizada compromete a escola com uma metodologia que passa pela exposição constante para o aluno do maior número possível de experiências linguísticas na variedade padrão.

Não se trata de excluir das tarefas da escola as reflexões sobre a linguagem, isto é, a descrição de sua estrutura ou a explicitação de suas regras. Trata-se apenas de estabelecer prioridades, deixando claro que não faz sentido, dado o objetivo da escola, descrever ou tentar sistematizar algo de que não se tenha o domínio efetivo. Um exemplo de atividade sugerido pelo autor é a comparação de várias variedades da mesma construção, das alterações em uma oração e a análise de resultados.

Neves (2002) defende o tratamento funcional para a gramática em sala de aula, ou seja, defende que se trate a língua na situação de produção e no contexto comunicativo. Para a autora, não se deve restringir os estudos sobre o funcionamento dos diversos itens gramaticais fora do contexto ou somente no nível oracional. Em relação à metodologia a ser implementada, a sugestão é que a escola se esforce para promover experiências e vivências para o aluno 
que lhe assegure um domínio linguístico capaz de garantir a produção de textos adequados às situações comunicativas. Uma interessante observação feita pela autora concernente ao ensino é que nas escolas as atividades relacionadas à gramática estão relacionadas com a classificação das entidades gramaticais e não se passa a um nível de análise efetiva. Esse tipo de procedimento, repetido ano a ano, traz a sensação de que o ensino de gramática não serve para nada, pois tal atividade se esgota em muito pouco tempo. Para a autora, é necessário que se implemente uma análise dos elementos gramaticais e que se discuta a respeito de suas funçóes dentro do texto, para que os alunos possam entender o valor do estudo da gramática, sem perder de vista a concepção de gramática como sistema: "afinal se a finalidade do ensino é o bom uso da língua, parece evidente que se deva refletir sobre a língua em uso" (p.263).

Vieira e Brandão (2007) trazem análises sobre fenômenos linguísticos atuais do português brasileiro, tais como a variação na concordância nominal, na concordância verbal, no uso de pronomes, e conseguem aliar os conhecimentos da gramática normativa resultados de pesquisas linguísticas com a forma de abordagem de tais conteúdos em sala de aula. O objetivo maior das autoras é desenvolver uma metodologia fundamentada em bases científicas, considerando a dinâmica da língua e a adaptação das estratégias no nível pedagógico. Para atingir tal objetivo, as autoras partem da hipótese de que os alunos possuem uma gramática internalizada, concebida como um sistema de regras e princípios universais, que deve ser desenvolvido pelo aluno na escola. Para elas, ao ingressar na escola o aluno deve desenvolver sua capacidade comunicativa de forma que ele possa utilizar melhor a sua língua em todas as situações de fala e escrita, isto é, o aluno deve ser capaz de refletir sobre a capacidade linguística que ele já possui e domina no nível intuitivo, mas sobre a qual nunca antes se tinha debruçado para analisar o funcionamento.

Ainda de acordo com as autoras, a aula de língua portuguesa deve ser um exercício contínuo de descrição e análise desse instrumento de comunicação. Para isso, várias estratégias podem ser utilizadas, entre elas, levar o aluno a reconhecer a variação inerente à língua. Para as autoras, o ensino de língua deve se centrar menos em exercícios de metalinguagem e mais em atividades que levem o aluno ao domínio das várias modalidades de uso e da modalidade culta da comunidade de que ele faz parte.

Apresentamos no quadro a seguir um resumo do que foi explorado na presente seção. Na primeira coluna apontamos as fontes que nos serviram como referência de reflexão, na segunda e terceira colunas denominamos, 
respectivamente, a concepção de língua(gem) e de gramática de cada autor destacado; na coluna seguinte, as metodologias apontadas e, por fim, os exemplos de atividades práticas que os mesmos autores propuseram.

\section{QUADRO 1}

A língua portuguesa: língua(gem), gramática, metodologia e exemplos práticos

\begin{tabular}{|c|c|c|c|c|}
\hline Fonte & $\begin{array}{l}\text { Concepção de } \\
\text { língua(gem) }\end{array}$ & $\begin{array}{c}\text { Concepção } \\
\text { de gramática }\end{array}$ & $\begin{array}{c}\text { Metodologia e } \\
\text { prática }\end{array}$ & Exemplos \\
\hline PCNs & $\begin{array}{l}\text { Perspectiva } \\
\text { sociointeracionista } \\
\text { de linguagem }\end{array}$ & $\begin{array}{l}\text { Gramática } \\
\text { descritiva }\end{array}$ & $\begin{array}{l}\text { Saber linguístico do } \\
\text { aluno como ponto } \\
\text { de partida para o } \\
\text { trabalho docente. }\end{array}$ & $\begin{array}{l}\text { Comparar os níveis } \\
\text { semânticos, morfológicos } \\
\text { e sintáticos de diferentes } \\
\text { variedades linguísticas de } \\
\text { diferentes línguas. }\end{array}$ \\
\hline Possenti & $\begin{array}{l}\text { Língua }(\text { gem }) \\
\text { como forma de } \\
\text { interação }\end{array}$ & $\begin{array}{l}\text { Gramática } \\
\text { internalizada }\end{array}$ & $\begin{array}{l}\text { Exposição a extenso } \\
\text { e variado panorama } \\
\text { de dados. }\end{array}$ & $\begin{array}{l}\text { Comparar diferentes } \\
\text { variedades da mesma } \\
\text { construção, alterações } \\
\text { numa oração e analisando } \\
\text { os resultados, em função } \\
\text { de distintos contextos e } \\
\text { situações extra-linguísticas. }\end{array}$ \\
\hline Neves & $\begin{array}{l}\text { Língua (gem) como } \\
\text { instrumento de } \\
\text { comunicação e } \\
\text { como forma de } \\
\text { interação. }\end{array}$ & $\begin{array}{l}\text { Gramática sob } \\
\text { perspectiva } \\
\text { funcional }\end{array}$ & $\begin{array}{l}\text { Promover experiências } \\
\text { para o aluno para } \\
\text { desenvolver domínio } \\
\text { linguístico capaz de } \\
\text { garantir a produção } \\
\text { de textos adequados } \\
\text { a diferentes situações. }\end{array}$ & $\begin{array}{l}\text { Analisar os elementos } \\
\text { gramaticais e suas } \\
\text { funçōes dentro do texto. }\end{array}$ \\
\hline $\begin{array}{l}\text { Vieira e } \\
\text { Brandão }\end{array}$ & $\begin{array}{l}\text { Língua (gem) como } \\
\text { instrumento de } \\
\text { comunicação }\end{array}$ & $\begin{array}{l}\text { Gramática } \\
\text { internalizada } \\
\text { e descritiva }\end{array}$ & $\begin{array}{l}\text { Metodologia } \\
\text { fundamentada em } \\
\text { bases científicas con- } \\
\text { siderando a dinâmica } \\
\text { da língua e a adaptação } \\
\text { das estratégias no nível } \\
\text { pedagógico. }\end{array}$ & $\begin{array}{l}\text { Levar o aluno a } \\
\text { reconhecer a variação } \\
\text { inerente à língua; } \\
\text { domínio das várias } \\
\text { modalidades de uso e } \\
\text { da modalidade culta. }\end{array}$ \\
\hline
\end{tabular}

De acordo com as discussóes apresentadas e resumidas no quadro acima, pode-se perceber que todos os autores se colocam contrários ao ensino de gramática baseado exclusivamente na metalinguagem. Outro aspecto de consenso é que todos partem do pressuposto de que a capacidade para adquirir uma língua é algo inato, ou seja, de que os alunos, ao chegarem à escola, já possuem conhecimentos gramaticais, e que, portanto, o papel da escola é desenvolver essa capacidade dos estudantes, além de propiciar recursos para o desenvolvimento de suas habilidades orais e escritas, em diferentes níveis. Por 
fim, todos os autores apontam caminhos e metodologias a serem implementadas. Diante dessas novas perspectivas de ensino propostas, o que parece faltar são estudos que analisem os resultados decorrentes de tais orientações e que testem a adequação dos métodos e técnicas na prática de sala de aula.

\section{Possíveis parâmetros para a constituição de novas práticas pedagógicas na formação inicial do professor de língua}

Uma diferente concepção de linguagem pode construir não só uma nova metodologia, mas, principalmente, conforme destacamos no início desse trabalho, pode ser capaz de modificar o próprio conteúdo ensinado. Dessa forma, antes de explorarmos possíveis parâmetros norteadores de uma nova prática escolar, nos debruçaremos criticamente sobre as três orientações metodológicas mais frequentes para o ensino da gramática:

1) Escola Tradicional: ensina-se a teoria gramatical para que os alunos usem a língua com eficácia. É uma concepção normativa que parte do pressuposto de que o aluno transferirá seu saber para comportamentos e a teoria será, pois, facilmente transformada em prática. A reflexão a ser feita é acerca da real possibilidade dessa concepção na realidade escolar. A experiência demonstra que tal postura não tem proporcionado os resultados pretendidos. Os alunos realizam operaçôes morfossintáticas, mas não aplicam tais aprendizados em suas produções textuais.

2) Escola Nova: a segunda orientação valoriza a proposta de que se aprende a fazer fazendo, ou seja, busca-se o uso linguístico para se chegar à gramática. Apesar da inovação ideológica, tal postura não modificou o sistema de ensino. A teoria gramatical continuou sendo prestigiada, apenas tomou-se exemplos como ponto de partida para ensinar a gramática. Além disso, tais exemplos baseiam-se mais em textos literários (língua padrão) que em produçóes linguísticas dos próprios alunos.

3) Metodologia inovadora: valoriza estritamente o uso, a produção linguística em detrimento da prescrição da língua. A realidade só a torna ineficaz porque valoriza estruturas preestabelecidas e não as dificuldades e necessidades dos estudantes.

Diante dessas diferentes abordagens teórico-metodológicas, percebemos que o resultado aponta para alunos ainda incapazes de usar a língua para resolver seus problemas de comunicação, interagindo socialmente e expressando seu 
pensamento em qualquer situação prática, de diferentes graus de formalidade e aponta para professores descrentes, desmotivados e perdidos no que diz respeito aos caminhos metodológicos que sua formação inicial apontou.

Podemos, então, lançar mão das seguintes questôes orientadoras de novas abordagens:

1) como relacionar, nos cursos de graduação de Letras, as diferentes teorias linguísticas e o ensino de gramática?;

2) de que forma a interpenetração de fronteiras disciplinares (transdisciplinaridade) pode favorecer o formando do curso de Letras, especialmente no que concerne à aproximação das ideias da Pedagogia, da Linguística e da Linguística Aplicada?;

3) como favorecer, no contexto da contemporaneidade, mudanças significativas no ensino de gramática nas escolas brasileiras?

Iniciamos as reflexões que visam responder tais questões tentando encontrar uma compatibilidade entre duas óticas da linguagem: a inatista e a discursiva.

De acordo com a perspectiva inatista da linguagem (CHOMSKY, 1980), o ser humano possui uma faculdade da linguagem que lhe é inata $e$ característica da espécie. Essa capacidade permite que em um curtíssimo espaço de tempo dominemos a gramática de uma língua, que é um sistema extremamente complexo, pois engloba aspectos de morfologia, sintaxe, semântica, fonologia e pragmática. Apesar dessa complexidade, qualquer criança com cerca de quatro anos já sabe usar sua língua para a expressão de seus pensamentos, salvo, é claro, os casos patológicos.

Apesar de o processo de aquisição não estar completo quando a criança entra na escola, ela já domina a gramática da língua. Considerando esse fato, a questão do ensino de gramática deve ser repensada principalmente em relação aos conteúdos gramaticais a serem ensinados. Pois, se a criança já possui uma gramática e já usa a língua, não se vai ensinar gramática à criança, o que vai ser feito pelo professor é o desenvolvimento das habilidades linguísticas da criança em relação à sua expressão oral e escrita. Outro ponto a ser trabalhado em sala de aula é a crescente conscientização dos alunos sobre aspectos envolvidos na expressão linguística e os usos que se pode fazer desses elementos, para que o aluno conheça as alternativas que a língua oferece para que ele possa se expressar. O papel do professor de gramática deve ser o de auxiliar os alunos no desenvolvimento de sua consciência linguística e no desenvolvimento de 
técnicas de expressão. Para que o aluno alcance tais objetivos, pode-se até usar a metalinguagem, mas esta dever servir apenas como um instrumento de ensino, e não como um objetivo de ensino.

Além disso, é importante desenvolver as capacidades de linguagem dos alunos por meio da interação dessa nova modalidade de análise linguística com a análise do discurso produzido pelo aluno. Ou seja, o aluno deve ser levado a perceber de que forma as marcas textuais podem orientá-lo a desvendar textos e contextos. Ao se aliar as concepções inatista e discursiva da linguagem para a prática de ensino, o processo de domínio crítico e efetivo da língua(gem) será extremamente enriquecido. Dessa maneira, o professor de língua deve, primordialmente, considerar a gramática interna do aluno, suas relações lógicas e regras internalizadas para, a partir daí, desafiar essa potencialidade linguística por meio de práticas discursivas no seu trabalho em sala de aula. Como, então, propor essa aliança e esses novos desafios discursivos?

De acordo com a perspectiva discursiva, o discurso é uma forma de prática social que não apenas reflete ou representa entidades e relaçōes sociais como também as constrói ou constitui. Essa concepção implica que o discurso pode ser tanto um modo de representação como um modo de ação sobre o mundo social (FAIRCLOUGH, 2001, p. 92).

Assim, os discursos são socialmente constitutivos em três aspectos fundamentais: o discurso constrói as diversas identidades sociais, o discurso constitui também as diferentes relaçôes sociais, podendo mesmo modificar as existentes por meio de novas formas de interação, e, por fim, o discurso colabora para a construção dos sistemas de conhecimentos e crenças do mundo.

No que diz respeito ao trabalho escolar do professor de língua, a perspectiva discursiva destaca que a relação entre o texto e o mundo social é mediada pela interação, ou seja, a forma como os textos são produzidos e interpretados depende dos mecanismos sociais em que o texto está engajado e a natureza textual depende do seu processo de elaboração que sempre fornece pistas para sua interpretação (FAIRCLOUGH, 1995).

No escopo da gramática, aspectos de conteúdo gramatical são focalizados por representar uma combinação de sentidos relativos ao nível das ideias, das relações, e do texto propriamente dito, ou seja, a escolha da estrutura oracional, por exemplo, implica escolha de identidades sociais, de relações e de crenças que estão materializadas no texto.

Em termos metodológicos, essa nova abordagem linguística deve levar em consideração práticas que tomem como material didático a produção de texto do aluno e uma infinidade de textos escritos e orais situados no bojo da 
realidade escolar, partindo da necessidade dos alunos, e não de uma lista de tópicos externa, ditada por outrem. O professor é sujeito ativo da escolha e seleção dos processos didáticos, é um 'intelectual' do currículo (GIROUX, 1997) e estabelece com o aluno uma relação menos assimétrica que na perspectiva tradicional.

Importante destacar ainda, que há uma preocupação em oportunizar ao aluno a exploração de uma variedade de gêneros textuais e de uma gama de variedades linguísticas, sendo que o objetivo é conscientizá-lo criticamente acerca das associações entre variedade linguísticas e práticas sociais, além de suscitar uma reflexão, que vai além do que está proposto nos $\mathrm{PCN}$, que diz respeito às causas e implicações da escolha da norma padrão como a norma a ser 'ensinada' na escola. Não se trata de não ensiná-la, mas, sobretudo, de levar para a sala de aula uma discussão crítica sobre o que é 'norma', 'erro', 'correção' etc., considerando raízes e consequências da associação das ideias: 'variação linguística' e 'preconceito linguístico'

No que concerne à segunda questão, consideramos que poderíamos aliar a abordagem ora proposta para o ensino de gramática às ideias do educador Freire (1997), para quem o contexto teórico não é nada mais do que um distanciamento de nossa prática - e de nossas ideologias, em que nos tornamos epistemologicamente curiosos para apreender a própria razão de ser dessa prática habitualizada. Assim, o contexto teórico está longe de ser um "puro fazer"; ele é, ao contrário, um contexto de "que-fazer", de prática e de teoria. Com essas palavras de Freire, podemos entender que as teorias linguísticas têm, de certa maneira, como base de motivação e como foco a prática de língua(gem) em si.

Do ponto de vista político e social, Freire (1997) ressalta que pensar nas escolas como esferas públicas engajadas com o desenvolvimento de práticas críticas e capazes de colaborar para a cidadania e a democracia social exige estar consciente do lugar em que ainda nos encontramos e do quanto falta percorrer para alcançar essas metas.

Chouliaraki e Fairclough (1999) também destacam que toda teoria é, ela própria, uma prática. Assim como as demais práticas, a teoria está inserida em uma série de relaçôes com as práticas econômicas, sociais, políticas e culturais que determinam sua constituição interna, as quais podem ter efeitos ideológicos que recaem sobre a própria teoria. Nesse sentido, podemos mencionar um conceito que tem sido explorado nas reflexões mais atuais na área da Análise de Discurso Crítica: o conceito de fortalecimento (FAIRCLOUGH, 2000; 2001; 1995; 1992). 
Fairclough (2001, p. 94) define como um dos seus focos principais de interesse o discurso como um modo de prática política e ideológica que é constituído e transformado no bojo das relações de poder e nas lutas pelo poder. Como prática política, o discurso "estabelece, mantém e transforma as relações de poder e as entidades coletivas" e, como prática ideológica, o discurso "constitui, naturaliza, mantém e transforma os significados do mundo". Nesse sentido, a noção de fortalecimento relaciona-se à redistribuição de poder para grupos oprimidos que são dominados por grupos com maior poder e está voltada para a autonomia do 'eu' e para o despertar de uma autoconsciência. Fortalecimento é, então, sob essa ótica, a habilidade de pensar e de agir criticamente.

Com relação à aplicação dessa concepção de fortalecimento no campo da educação, Rajagopalan (2002) destaca que o objetivo principal é ajudar tanto os professores como os alunos, que atuam em condições marginalizadas, no desenvolvimento de formas de resistência a injustiças a que são submetidos e, com seus próprios esforços, melhorar as condiçōes de vida e recuperar sua dignidade.

Freire (1997) também utiliza a noção de fortalecimento ao ressaltar que esse conceito passa das esferas do individualismo para a coletividade, sem, contudo, se apresentar como uma solução espontânea para educação democrática. Fortalecimento "indica um processo político das classes dominadas que buscam a própria liberdade da dominação, um longo processo histórico de que a educação é uma frente de luta" (FREIRE, 1997, p. 138).

Freire (1997, p. 134-135) não acredita na autolibertação, pois, para ele, "a libertação é um ato social". O fortalecimento não é suficiente para a mudança social em termos gerais, todavia ele é "absolutamente necessário para o processo de transformação social". Em outras palavras, desenvolver a consciência crítica, bem como ter a sensação de ter mudado é fundamental na modificação mais ampla da sociedade.

Essa concepção de fortalecimento vai ao encontro dos estudos em torno da Consciência Linguística Crítica (Critical Language Awareness, doravante CLC) que partiram de uma proposta de linguistas da Universidade de Lancaster (CLARK et al., 1991, p. 1) ao considerarem a linguagem como constitutiva em relação à sociedade, no âmbito ideológico e das relações de poder. $\mathrm{O}$ termo tem sido utilizado para "identificar uma abordagem de ensino de línguas que se fundamenta na atenção consciente às propriedades da linguagem e de seu uso". 
O desenvolvimento dessa concepção de educação fortalecedora implica diretamente a forma como o conteúdo gramatical deve ser apresentado em sala de aula. Especificamente em relação à metodologia de ensino de gramática, $o$ conceito de fortalecimento é crucial no direcionamento dos métodos a serem implementados. O que se vê em manuais de ensino baseia-se em uma metodologia que mais se preocupa em oferecer respostas aos fenômenos linguísticos estudados e dicas de como a língua deve ser usada do que em oferecer ao aluno a oportunidade de usar sua língua, de experimentá-la de usufruí-la e de avaliar os resultados dos diferentes usos e formas linguísticas possíveis. Ao aluno deve ser dada a possibilidade de (i) investigar a língua e as várias estruturas linguísticas que ele próprio utiliza e produz, assim como as estruturas utilizadas por outros produtores, (ii) desenvolver conceitos que the sejam úteis para que ele possa chegar às suas próprias conclusóes.

Outra prática a ser adotada em relação ao ensino de gramática, sob o conceito do empoderamento, é a prática da pesquisa, da busca de respostas. Lobato (2003), em uma conferência apresentada na Socidade Brasileira para o Progresso da Ciência (SBPC), apresenta três técnicas que favorecem o trabalho com a gramática em sala de aula no que concerne ao desenvolvimento da competência gramatical do aluno. São elas: procedimento de descoberta, eliciação e técnica de resultados. O procedimento de descoberta, como o próprio nome já diz, se relaciona com forma de apresentação do conteúdo gramatical ao aluno. Em vez de se apresentar uma regra e seus usos, apresentase um conjunto de dados organizados e o aluno irá descobrir o fenômeno gramatical em questão, e irá desvendar os elementos gramaticais que entram em jogo. Ou seja, os dados são apresentados ao aluno e ele, usando sua competência gramatical, terá o prazer de descobrir os recursos linguísticos que muitas vezes faz uso inconscientemente. A técnica de eliciação, que é amplamente usada em cursos de línguas estrangeiras, consiste na identificação, por parte dos alunos, e com a ajuda do professor, dos aspectos linguísticos envolvidos em um determinado contexto e na posterior tentativa de organização das regras depreendidas. Nesse, caso a metalinguagem pode ser utilizada. Por fim, com a técnica de resultados, o aluno é motivado a usar a língua e a refletir sobre os resultados obtidos, com os efeitos semânticos obtidos a partir das diferentes construções implementadas. Trata-se de uma oportunidade de autoconhecimento linguístico e de reflexão sobre os efeitos do uso de determinadas estruturas linguísticas. 
Podemos, assim, apontar para a resposta da terceira questão levantada no início da seção: como favorecer, no contexto da contemporaneidade, mudanças significativas no ensino de gramática nas escolas brasileiras?

Considerando a proposta transdisciplinar esboçada acima, dois aspectos parecem ser relevantes para que haja uma verdadeira educação de nossos alunos em relação ao processo de ensino-aprendizagem de gramática. O primeiro é que é necessária a conscientização dos docentes da necessidade de trabalhar, conscientemente, com base em uma abordagem de língua específica. A abordagem que ora propomos busca contemplar o conhecimento gramatical dos alunos, fruto de sua faculdade da linguagem e das experiências linguísticas, com a promoção de análises críticas que interpretem esses diferentes usos nos textos produzidos pelos alunos e pela sociedade. $\mathrm{O}$ segundo aspecto, decorrente da abordagem adotada, diz respeito à relevância da utilização de uma metodologia adequada e da seleção de conteúdos a serem ensinados. No caso da proposta ora apresentada, será necessário que a metodologia esteja calcada em um aprendizado por meio da experiência do uso e da reflexão crítica sobre os diferentes usos da língua no contexto social efetivo.

$\mathrm{Na}$ prática escolar o objetivo inicial é problematizar a aparente transparência e neutralidade dos textos, a fim de reconstruir processos subjacentes, geralmente localizados no nível inconsciente do leitor. Encorajando a autoconsciência sobre o posicionamento das pessoas no discurso, verificando determinadas escolhas de processos gramaticais em lugar de outros, sob uma ótica crítica, é possível desenvolver no aluno um interesse real pela análise gramatical situada, além de desenvolver sua postura crítica de cidadão (CLARK et al., 1991).

A CLC se constrói por meio de um estudo crítico da linguagem. As atividades de conscientização estão inseridas no próprio corpo de conhecimento escolar. Nesse sentido, o conhecimento é uma construção social ligada a normas e valores que precisam ser debatidos na educação crítica. $\mathrm{O}$ que se chama de letramento crítico é exatamente o que os proponentes da CLC chamam de "uma conscientização crítica do mundo e das possibilidades de mudá-lo" não só em termos linguísticos como em relação à educação em geral (CLARK et al., 1991, p. 52).

Clark et al. (1991, p. 12-13) também ressaltam que a consciência linguística crítica é formada a partir das capacidades de linguagem existentes e das experiências dos aprendizes. A CLC deveria estar relacionada, segundo os autores, a um discurso com objetivos, pois, se assim não for, "a conscientização não leva a lugar nenhum, exceto ao fatalismo e a aceitação". 
Quanto aos elementos a serem incluídos em um programa de CLC, Clark et al. (1991, p. 14) destacam três categorias básicas: (i) conscientização social do discurso; (ii) conscientização crítica da diversidade; (iii) conscientização de, e prática para, a mudança, a partir da ideia de que "a mudança na linguagem é o resultado de lutas sociais e de mudanças nas relações de poder". A partir desse programa proposto pelos referidos autores, podemos pensar no ensino de gramática situado em cada uma das categorias elencadas, uma vez que se torna essencial pensar sobre a conscientização dos processos discursivos no que tange às estruturas gramaticais subjacentes.

Essas são, pois, as principais ideias em termos do processo de CLC. Dessa maneira, para que mudanças no ensino de gramática sejam possíveis, é necessário o engajamento com uma conscientização crítica da linguagem e do mundo onde sujeitos sociais interagem e encontrem a possibilidade de mudar.

\section{Considerações Finais}

No presente artigo, apresentamos algumas discussōes sobre o ensino de gramática na atualidade. A partir de uma reflexão crítica sobre os modelos tradicionais de ensino de gramática, tentou-se mostrar que, apesar dos significativos avanços no campo das pesquisas sobre a linguagem e da constante presença dos estudos linguísticos nos curso de graduação, parece estar havendo certa dificuldade na transposição e adequação dos conhecimentos obtidos na universidade para a sala de aula. A reflexão sobre o que deve ser ensinado e como deve-se ensinar a língua portuguesa ainda não são elementos que estejam apresentando reflexos no ensino de gramática. Apesar de essa abordagem estar presente nas propostas curriculares dos cursos de Letras, parece ainda haver uma lacuna na formação dos futuros docentes no que se refere ao desenvolvimento de metodologias de ensino.

Com base em propostas de vários pesquisadores, esboçamos uma abordagem de ensino transdiciplinar que tenta conciliar a proposta do inatismo com proposta de análise crítica do discurso, alinhavados com os princípios sociointeracionistas. Essa nova metodologia busca subsidiar novas metodologias e tenta remodelar o próprio conteúdo ensinado, sob uma ótica fortalecedora da educação. Tendo em vista a concepção de que a língua é algo inato e que ao chegarem à escola os alunos já possuem uma gramática, surgem questionamentos a respeito da seleção do conteúdo que vai ser ensinado ao aluno e sobre o tipo de conhecimento que o aluno ainda pode adquirir. Questóes como as acima apresentadas merecem estudos e pesquisas. 


\section{Referências Bibliográficas}

BRASIL, Ministério da Educação e Desporto. Parâmetros Curriculares Nacionais. $3^{\circ}$ e $4^{\circ}$ ciclos do ensino fundamental. Brasilia: SEF, 1998.

CHOMSKY, N. Rules and representations. Nova Iorque: Columbia University Press, 1980.

CLARK, R. et alli. Critical language awareness: towards critical alternatives. Language and Educations 5, University of Lancaster, p. 41-54, 1991.

CHOULIARAKI, L.; FAIRCLOUGH, N. Discourse in late modernity: rethinking Critical Discourse Analysis. Edinburgh University Press, 1999.

DUTRA, D. P.; MELLO, H. R. (Org.). A gramática e o vocabulário no ensino de inglês: novas perspectivas. 1. Ed. Belo Horizonte, 2004.

FAIRCLOUGH, N. Discourse and text: linguistic and intertextual analysis within discourse analysis. Discourse and Society, v. 3-2, p. 193-217, 1992.

FAIRCLOUGH, N. Critical discourse analysis. London: Longmans, 1995.

FAIRCLOUGH, N. Multiliteracies and language: orders of discourse and intertextuality. In: COPE, B.; KALANTZIS, M. (Ed.). Multiliteracies: literacy learning and the design of social futures. London: Routledge, 2000. p. 162-181.

FAIRCLOUGH, N. Discurso e mudança social. Coordenadora de tradução: Izabel Magalhães. Brasília: Ed. UnB, 2001.

FREIRE, P. A pedagogia da autonomia. Rio de Janeiro; São Paulo: Paz e Terra, 1997.

LIMA. S. N. A Gramática Sistêmico-Funcional como instrumento de análise de relatos de professores em pesquisa sobre o ensino (ou não) da gramática teórica na educação básica. D.E.L.T.A, São Paulo, v. 25 n. 1, 2009.

GERALDI, J. W. Portos de passagem. São Paulo: Martins Fontes, 1991.

GIROUX, H. Pedadogy and the politics of hope. EUA/Colorado e UK, Westview Press, 1997.

ILARI, R. A linguística e o ensino da língua portuguesa. São Paulo: Martins Fontes, 1992.

LEFFA, V. J. Como produzir materiais para o ensino de línguas. In: LEFFA, V. J. (Org.). Produção de materiais de ensino: prática e teoria. 2. ed. Pelotas: Educat, 2008. v. 1, p. 15-41.

LOBATO, L. Concepçôes de linguagem e ensino. 1a RR da SBPC. Campina Grande. 2003 (manuscrito).

KATO, M. A. Resenha do livro: VIEIRA, S.R.; BRANDÃO, S.F. (Org.). Ensino de Gramática: descrição e uso. D.E.L.T.A, v. 23, n. 2, p. 404-405, 2007. 
MENDONÇA, M. Análise linguística no ensino médio: um novo olhar, um outro objeto. In: BUNZEN, C.; MENDONÇA, M. (Org.). Português no ensino médio e formação do professor. São Paulo: Parábola Editorial, 2006.

MONTEMÓR, H. A. S. M. Representaçôes discentes acerca da importância da aprendizagem da teoria gramatical analisada pela Gramática Sistêmico-Funcional. D.E.L.T.A, São Paulo, v. 25, n. 1, 2009.

NEVES, M. H. M. A gramática na escola. São Paulo: Contexto, 2002.

NEVES, M. H. M. Resenha do livro: VIEIRA, S.R.; BRANDÃO, S.F. (Org.). Ensino de Gramática: descrição e uso. São Paulo: Contexto. D.E.L.T.A, v. 24, n. 1, p. 131-133, 2008.

POSSENTI, S. Gramática e Análise do Discurso. Cadernos de Estudos Linguisticos, 1992.

POSSENTI, S. Por que (não) ensinar gramática na escola. Campinas: Mercado de Letras, 1996.

RAJAGOPALAN, K. Teorizando a resistência. In: SILVA, D. E. G.; VIEIRA, J. A. (Org.). Análise do discurso: percursos teóricos e metodológicos. Brasília: UnB. Oficina Editorial do Instituto de Letras; Ed. Plano, 2002. p. 203-220.

SILVA, R. V. Contradiçôes no ensino de português: a língua que se fala x a língua que se aprende. São Paulo: Contexto, 1997.

TRAVAGLIA, L. C. Gramática e interação: uma proposta para o ensino de gramática no $1^{\circ}$ e $2^{\circ}$ graus. 8. ed. São Paulo: Cortez, 2002.

VIEIRA, S. R.; BRANDÃO, S. F. (Org.). Ensino de Gramática: descrição e uso. São Paulo: Contexto, 2007.

Recebido em 4 de abril de 2010. Aprovado em 17 de maio de 2010. 